frameworks, as Bowler himself suggests. But he does not carry through this approach systematically, so there is no clear thematic thread running through the volume. The bulk of the book is a fairly conventional (but informed and highly competent) survey of the history of geology, fossils and natural history, culminating in evolution and the darwinian revolution. The notion of the environment and its conceptualization in scientific studies lurks in the background, emerging only in the twentiethcentury as the 'environmental sciences'.

The most striking feature of Brock's text is his focus on the period of modern chemistry following the "chemical revolution' of Lavoisier (and others) in the late eighteenth century. Fully half of the book is given over to an excellent account of the principal developments of the nineteenth century: the chemical atomic theory, organic analysis, classification, structural organic chemistry, the periodic table, the origins of physical chemistry (in the chemistiy of solutions), with glances at industrial chemistry, chemical education and publication. The distinctive feature of his approach is the very limited attention given to conceptual confusions over vitalism and organic models, in favour of an emphasis on the more technical questions of analysis, the concerns of the laboratory chemist. The account of twentieth-century developments is especially interesting, and though the treatment is selective - here we find discussions of Pauling, Robinson, Ingold and Woodward - it is presented in especially racy style. The concerns of Brock's text and his method of exposition (with necessary deployment of a limited chemical vocabulary) will make his book an excellent course book for history of chemistry courses taught in chemistry departments.

Bowler's text is much more suitable for use in general history of science courses. His synthesis of geology, fossils and evolutionary history is very well done; the breadth and wide chronological range of the book make it unique. The account of the most recent developments is particularly imaginative, and sparks off some critical engagements with controversial ethical questions surrounding the environment. Here the long historical perspective is especially valuable, pointing up the need to avoid simplistic constructions translated into political slogans and party programmes. Brock too concludes his book with a glance at the environmental implications of chemistry. And both authors are keen to use historical awareness to promote philosophical reflection.

Peter Harman is in the Department of History, University of Lancaster, Lancaster LA1 4YG, UK.

\section{Missing links}

Alison Jolly

Vislons of Caliban: On Chimpanzees and People. By Dale Peterson and Jane Goodall. Houghton Mifflin: 1993. Pp. 367. $\$ 22.75$.

VISIONS of Caliban is beautifully written, easily read and ethically challenging - it just might become primatology's Silent Spring. It confronts us with the plight of chimpanzees in Africa and the West. Although the stories are horrifying, they are told with relative restraint. Peterson

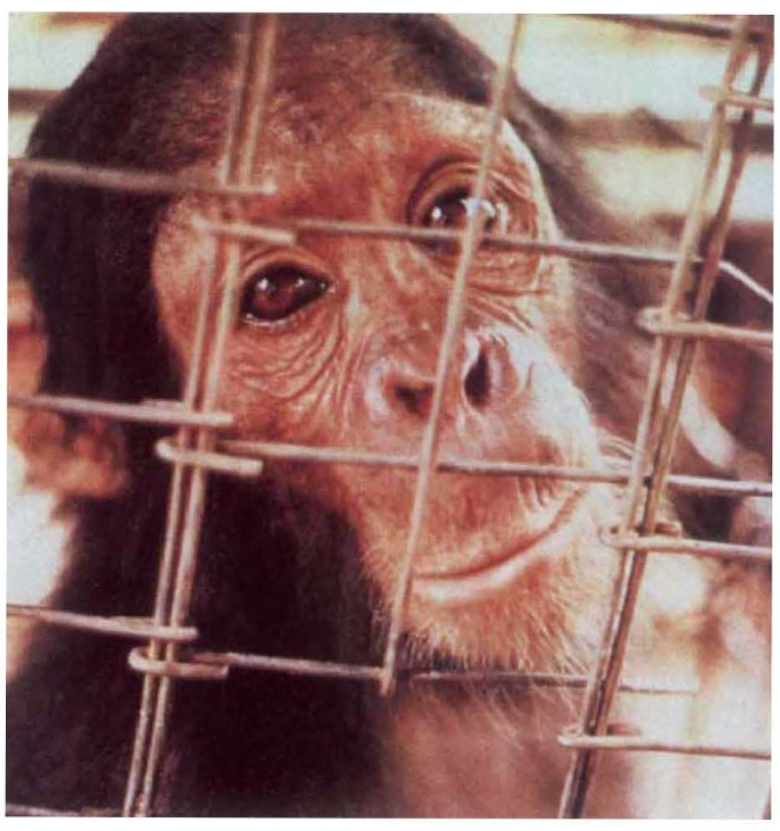

Condemned creature?

and Goodall (who write antiphonally) do not insist that all apes should be free they even single out a few captive primate centres for praise. Rather, their central question is this: if biomedical research can benefit from the great apes precisely because they so closely resemble us, do we not have an obligation to treat apes according to their quasihuman emotional needs? Extremists who raid laboratories to lay hands on research animals can be fought by locks and guards and secrecy; but those who argue as cogently as Peterson and Goodall can be answered only by clear explanation of what laboratory apes can contribute to human welfare, whether this justifies our imprisoning them and - if it does - what conditions we owe them in captivity.

"History is marked by an amnesia about human origins and dependence. This great forgetting might be compared to an adult's powerful amnesia about infancy and early childhood", writes Peterson. As Gillian Beer has pointed out, the missing link can remain forever denied, with its "freight of curiosity, reluctance, and disgust". This allows some of us the gusto of Alfred Russell Wallace when he shot a monkey in the Amazon: "The poor little animal was not quite dead, and its cries, its innocentlooking countenance and delicate little hands were quite child-like. Having often heard how good monkey was, I took it home, and had it cut up and fried for breakfast"

Peterson counters our amnesia by choosing Caliban as his missing link. This creature from The Tempest is part of Western mythology. We accept him as a half human, half beast, enslaved by the magician Prospero yet acknowledged as his kin. Similarly, we value chimpanzees because they are close to humans, yet treat them as animals to be used at our will.

Goodall and Peterson give us an up-to-date overview of research on the intelligence of chimpanzees. Chimpanzees, like Caliban, know "every fertile inch o'th'island": they have mental maps of the location of fruit trees and even know and use medicinal herbs. They hunt cooperatively for colobus monkeys and make tools that differ from one chimpanzee culture to another. Indeed, according to W. C. McGrew, some artefacts would be unattributable to humans or chimpanzees if they lost their museum labels. Chimpanzees have a sense of self, recognizing their own image in a mirror. They can learn the rudiments of language and understand novel sentences in spoken English if taught by a patient Prospero. Shakespeare was not far off when Caliban cries, "Thou taught'st me language, and my profit on't is, I know how to curse!" One of the common innovations of language-trained apes is the use of the sign for 'faeces' as an insult.

The heart of the book is the story of the 20 chimpanzees shipped by Franz Sitter from Sierra Leone in West Africa to Immuno Inc. in Austria. (Sierra Leone held roughly 2,000 wild chimps at the time, and perhaps ten apes die for each one that reaches a foreign country.) The authors reprint Shirley McGreal's exposé in the Journal of Medical Primatology in 1983. This letter caused Immuno to sue - each for $\$ 4$ million McGreal, the journal's editor, publisher and distributor, and, incidentally, New Scientist, which had quoted criticisms of the company. Five years of litigation later, the Supreme Court of New York 
threw out the case on the grounds that although McGreal's letter "might well have been damaging to Immuno, the facts she stated were 'evidently true'. . . [and] did not justify a libel suit". Meanwhile, all but one of the original defendants had settled out of court. It would make a great movie - but those cast as villains are still around.

There is more: the accounts, with names, of those who own chimpanzees as pets or use them as comic entertainers. All these people insist that they love the animals they keep. For some this is clearly true, for others, less so. But what emerges even more clearly is that no adult ape is a trustworthy pet - a chimpanzee is far stronger than a man, and has its own lusts and violent outbursts. One of the happiest captive chimpanzees may be Mr Jiggs, a female who works at birthday parties and bar mitzvahs with her jaws wired shut and an electric prod strapped to her back. The fate of a chimpanzee that is shut in a cage without social contact is far worse.

Goodall has sometimes been criticized for campaigning to help chimpanzees in captivity rather than addressing the destruction of wild populations; Peterson, however, has interviewed African hunters, traders and breeders and has located grisly trophies in the Brazzaville market. Of 25 countries that recently held wild chimpanzees, extinction of the species has now occurred in at least four and seems imminent in five more. All populations are declining in number world totals may be 150,000 to 250,000 . Goodall, on seeing the eroded smallholdings and dwindling fisheries of Lake Tanganyika, laments that "It would be a happy consolation to imagine that such is the price of 'progress', that the human inhabitants of Africa are somehow better off today than they were not so long ago when chimpanzees were a common species - but that is not the case. [Environmental] loss affects us all; human and animal alike."

Africans are responsible for most of the loss of chimpanzees and will be ultimately responsible for saving the wild habitats of these creatures; but Peterson and Goodall choose to play down the mote in the African subsistence farmer's eye and concentrate on the beam in our own. Western nations set the trend for the ever-increasing gobbling of resources - and it is up to us to decide whether chimpanzees should be owned, used and used up. Let it be a reasoned and cleareyed choice that respects these animals as conscious beings, our sibling species, the demi-humans in our power.

Alison Jolly is in the Department of Ecology and Evolutionary Biology, Princeton University, Princeton, New Jersey, 085441003, USA.

NATURE · VOL 362 - 15 APRIL 1993
Pole polemic

\section{Derek Fordham}

The Myth of the Explorer: The Press, Sensationalism and Geographical Discovery. By Beau Riffenburgh. Belhaven: 1993. Pp. 226. £37.50.

"A FEW toes aren't much to give to achieve the Pole!" So wrote Robert E. Peary, no doubt with the front page in mind, when several frost-bitten digits fell off in his sock after a disastrous winter journey. This was some years before his last attempt on the North Pole, following which he dispatched the apocryphal cable from Newfoundland: "Stars and Stripes nailed to the Pole". The fact that they were not and that at that moment Frederick Cook was claiming to have reached the Pole a whole year before Peary were issues that whipped the press, which had been supporting Peary, into a state of near apoplexy.

Riffenburgh's scholarly and detailed account of the emergence of the press as a player in the exploration game covers the period 1855-1910, when there were two main arenas in which heroic battles of exploration were fought Africa and the Arctic. Increasing press interest in exploration ensured that explorers became seen as nationalists fulfilling ideologies, promoted mainly by the press but often, it must be said, by themselves.

This link between press and exploration was forged in the nineteenth century by the James Gordon Bennetts, father and son, of The New York Herald. The father claimed to show the world how to obtain news, the son how to create it a philosophy nowhere more apparent than in the arguments that raged over whether Stanley had actually met Livingstone. This debate became one of the first sources of competition between the American and British press.

Bennett $\mathrm{Jr}$ then discovered the Arctic and history might have been quite different had he felt his wallet equal to Stanley's "readiness to undertake the discovery of the North Pole" in 1878. Bennett realized that the public was captivated by reports of struggles to master nature, and he saw that concentrating on the blanks on the map afforded exhilarating possibilities of establishing man's role as 'Master of Nature'. National heroes were created by means of journalistic hype and thus was established the role of the press in the creation of the modern image of the unknown world, helping to change it from the picturesque vision of the eighteenth century to the sensational perspective that still prevails.

In a manner not unlike that favoured by the press today, the achievements of Amundsen, Nansen and Stanley, among many others, were manipulated and misreported in different but no less effective ways. But of all the issues, African and Arctic, that Riffenburgh examines it is the Arctic and the Cook-Peary con-

\section{IMAGE UNAVAILABLE FOR COPYRIGHT REASONS}

French cartoon of the Peary-Cook flasco in the Arctic, 1909. The caption reads: 'Well, if someone's beaten troversy in particular that is the paradigm of the intrusive role of the press. Such contests as that which arose between Peary and Cook have traditionally been seen as struggles between explorers, but they were in reality equally struggles between their patrons, the newspapers, and were therefore dictated and shaped by the commercial interests of the proprietors.

Peary was a bold, impassioned and eminently dislikeable man who in 1909 set out on what he knew would be his last attempt to reach the North Pole. On this occasion, as in his previous 22 years of polar activity, he was vigorously supported by the press in the form of The New York Times and the National Geographic. At $87^{\circ} 47^{\prime}$ North, Peary's last supporting party turned back, leaving him as the only capable navigator. Failure now was unthinkable, with 